\title{
ESSAY
}

\section{Mankind's place in the Universe}

\section{Technological developments in astronomy have long helped to answer some of the greatest questions tackled by humanity, recounts Owen Gingerich.}

Just over 400 years ago, news swept across Europe of an astonishing device - two lenses within a tube - that almost magically brought distant views closer. Its exact origins are lost in a mist of controversy, but it is known that one Hans Lipperhey in Middelburg, the Netherlands, applied for a patent in October of 1608. His application was turned down on the grounds that the unnamed novelty was already common knowledge.

Seventeen months later a small booklet by an Italian mathematics professor announced wonderful discoveries made with this newly devised spyglass. The title page may have implied that the 'perspicillum' was Galileo Galilei’s own invention, but he should be forgiven any exaggeration, for what Galileo had done was to turn a popular carnival toy into a scientific instrument. In December 1609 he used his spyglass to discern craters, mountains and plains on the Moon. The 400th anniversary of these astonishing observations sets the stage for what the United Nations has designated the International Year of Astronomy.

By January 1610, Galileo had further found four bright moons of the planet Jupiter (it would be his contemporary, Johannes Kepler, who named them 'satellites'). Before that year was out Galileo had also found the phases of Venus, proving that it revolved about the Sun.

The implications of such findings were immense. Although Nicolaus Copernicus's De revolutionibus orbium coelestium ('On the Revolutions of the Heavenly Spheres'; 1543) - the work that proposed a Sun-centred or 'heliocentric' system - was already nearly seven decades old, it was taken only as a manual for computing positions of the planets; by no means was it thought to be a physically real description of the cosmos. How ridiculous to think of living on a globe that spun around once every 24 hours! And how could Earth keep the Moon in tow if it whirled around the Sun every year?

It was Galileo's work that made it intellectually respectable to believe in heliocentrism as a physical reality. Galileo saw that the Moon was
Earth-like, rather than a pure ball of crystalline aether: the perceived distinction between Earth, home of corruption and decay, and the eternal, aethereal heavens was crumbling. Jupiter had no trouble keeping its moons in tow, and everyone agreed that Jupiter was moving. Why could a moving Earth not keep its Moon on an invisible tether? Galileo's skillful polemics on this matter became full-blown in his 1632 Dialogue on the Two Chief World Systems - a work that failed to conclusively prove the in his A Perfit Description (1576), placed a "habitacle [home] for the elect" among the stars.

It is not surprising that clerical authorities for the most part resisted the new cosmology. More than this, the Roman Catholic authorities were furious that Galileo, a mere amateur theologian, had the audacity to tell them how to interpret scripture. It was clearly a turf battle. Galileo was brought to trial in Rome, allowed to plead innocent to charges of vehement suspicion of heresy, but convicted of disobeying orders (in teaching the Copernican cosmology), and sentenced to house arrest for the remainder of his life.

"New philosophy calls all in doubt," lamented the poet John Donne. "Tis all in pieces, all coherence gone.”

Galileo's persuasiveness was helped along by Kepler, whose landmark volume of theoretical astronomy was also published in 1609. His aptly named Astronomia nova or 'New Astronomy' relied heavily on looking at the physical causes of planetary motion - a critical departure from the past, when astronomers used strictly geometrical modelling to explicate the heavens. Even Kepler's teacher and mentor, Michael Maestlin, urged him to forget about physics and stick to astronomy (that is, geometry). But Kepler believed in a physically real cosmos, and even ahead of Galileo advocated the Sun-centred system.

Heliocentrism as it had come down from Copernicus, however, was flawed. Copernicus used entirely different geometrical models for the latitudes of planets than for the longitudes, whereas for a physically real system, the same model should work for both coordinates. According to Copernicus, the planets moved in circles (the main ones eccentrically placed with respect to the Sun), and Earth did not move faster when closest to the Sun. It was Kepler's requirement for plausible physical explanations that drove him ultimately to postulate an ellipse as the basic form of planetary orbits, ironing out these difficulties.

Alongside Galileo's telescopic observations, Kepler's improvements in planetary theory eventually brought about general acceptance of the Copernican cosmology. In the introduction to Astronomia nova, Kepler wrote: the hellfire below, whereas the realm of God and the elect lay beyond the starry firmament. Even Thomas Digges, the English astronomer who supported the "noble Copernican philosophy"

\section{Heavenly vision} The ecclesiastical vision of a heavy, central Earth upon which the human drama played fit nicely into this Aristotelian cosmos - volcanoes belching out smoke and flames hinted at 
"Perhaps there is someone whose faith is too weak to believe Copernicus without offending his piety. Let him stay at home and mind his own business. Let him assure himself that he is serving God no less than the astronomer to whom God has granted the privilege of seeing more clearly with the eyes of the mind."

Before and since, astronomical devices have been at the heart of mankind's literal search for our place in the Universe. It is not an inexpensive endeavour. Tycho Brahe boasted that his observations (which did not involve a telescope but rather carefully graduated naked-eye sightings using quadrants and other devices) cost the King of Denmark more than a ton of gold - a huge fortune in the sixteenth century. Today, telescopes can cost billions of dol-

lars. It could be argued that such devices are ultimately as useful (or useless) to human progress as poetry. But they are funded because, like the greatest poetry or the building of a Gothic cathedral, cosmology is a voyage of the human spirit, and as such, a point of personal or national pride. It is worth a great price to understand our place in the intricate web of time and space.

\section{The farthest reaches}

After Galileo's work and Kepler's refinements - replacing a convex objective lens and concave eyepiece with two convex lenses, allowing for a wider field of view and accommodating crosshairs - the next major leap forward for observational astronomy would not come for nearly two centuries. Towards the end of the eighteenth century, William Herschel, an inspired musician-turnedamateur-astronomer, began his seemingly quixotic quest to determine the three-dimensional structure of the Universe. In the process, he discovered a new planet - Uranus - an event that changed his status from amateur

\section{"Will we soon} answer the next psyche-shifting question: are we alone?"
Fresh views:

Thomas Digges's heliocentric Universe (above) and Galileo's perspicullum.

mirrors, and the ability of photography to capture images of stars and nebulae, astronomers finally marched through that portal. In 1859, in a chemical laboratory in Heidelberg, chemist Robert Bunsen and physicist Gustav Kirchhoff discovered the key to unlocking the chemical secrets of the Universe via the distinctive spectral lines associated with individual elements. Meanwhile, rich philanthropists poured cash into instruments of discovery, and from the new giant telescopes emerged a sequence of consciousness-raising discoveries. Among them was the immense size of the Milky Way, far beyond to professional. The most inventive astronomer of his age, Herschel set on a path to evergreater light-gathering power by building huge reflecting telescopes. He ended up counting thousands of stars and discovering hundreds of clusters and nebulae - the gateway to the vast outer Universe beyond the traditional sphere of naked-eye stars.

A century later, thanks to engineering advances, the discovery of how to silver glass anything dreamed of by Herschel. Then came the realization that the Milky Way was but one of myriad galaxies stretching beyond by millions (and even billions) of light years, rushing away from each other as if from a cataclysmic explosion billions of years ago.

This vast increase in the size and age of the perceived cosmos set the stage for an angst as deep as that caused by the displacement of the ancient human-centred cosmology:
43

what significance do rational, observing mortals have in the wilderness of a near-infinite space-time continuum? This existential question has been simmering for decades and undoubtedly drives our willingness to invest taxpayers' money in further cosmic explorations.

Today, the electronic revolution has provided charge-coupled devices to replace photographic plates that have nearly 50 times their efficiency; has made feasible the collection and handling of data in the trillions of bits; and has enabled high-speed adaptive optics to compensate for atmospheric variations, allowing astronomers to take full advantage of large-aperture Earth-based telescopes. The stellar and galactic denizens of the Universe can now be catalogued as never before. That has included, in recent years, the discovery and cataloguing of exoplanets - those beyond our Solar System.

NASA's Kepler mission, scheduled for launch in March 2009, is the first craft designed explicitly to look for Earth-like exoplanets. Don't expect radio communications from intelligent life to come from one of those planets. But other exciting signals could surely be found. Today, spectroscopy can be used to spy on the atmospheres of far-away planets, and look for chemical traces that may hint at signs of life even an extremely basic form of life could produce an oxygen signal in a planet's atmosphere. Such studies may help in answering the next psyche-shifting question: are we alone?

The International Year of Astronomy might well launch the next intellectual revolution in our understanding of our place in the Universe. Could this have as much of an impact on society as Galileo and Kepler's entrenchment of the heliocentric view? Only time will tell.

Owen Gingerich is professor emeritus of

astronomy and history of science at the HarvardSmithsonian Center for Astrophysics in Cambridge, Massachusetts, and author of God's Universe. e-mail: ginger@cfa.harvard.edu

See http://tinyurl.com/57589t for further reading. See also www.nature.com/astro09. 